\title{
Microwave Coagulation Therapy Combined with Laparoscopic Liver Resection for Hepatocellular Carcinoma in Cirrhotic Patients
}

Hong-wei Zhang ${ }^{\star}$, Ya-jin Chen, Xuan Luo and Jun Cao

Department of Hepatobiliary Surgery, Sun Yat-sen Memorial Hospital of Sun Yat-sen University, China

*Corresponding author: Hong-wei Zhang, Department of Hepatobiliary Surgery, Sun Yat-sen Memorial Hospital of Sun Yat-sen University, 107 Yanjiang Xi Road, Guangzhou, China, Tel: 00862034071170; Fax: 00862034071092; E-mail: hongweizhang88@126.com

Rec date: Mar 07, 2014, Acc date: Apr 23, 2014, Pub date: Apr 25, 2014

Copyright: (C) 2014 Zhang $\mathrm{H}$, et al. This is an open-access article distributed under the terms of the Creative Commons Attribution License, which permits unrestricted use, distribution, and reproduction in any medium, provided the original author and source are credited.

\begin{abstract}
Objective: Image-guided microwave coagulation therapy as a minimally invasive technique has been widely used for the treatment of small HCC in patients who have high surgical risks. However, tumor residual after thermal albation is still the main reason of HCC recurrence. Laparoscopic resection of the tumor after thermal ablation will take advantage of reducing the risk of tumor residual without increasing the risk of hepatic failure. The aim of this study was to evaluate the feasibility and safety of this technique.
\end{abstract}

Methods: From 2008 to 2010, 18 patients (15 men and 3 women; age range, 35-77 years) with HCC and associated severe liver cirrhosis underwent microwave coagulation therapy combined with laparoscopic liver resection. Inclusion criteria were solitary, peripheral or subcapsular HCC lesions localised to the left or anterior right segments; lesion size less than $4 \mathrm{~cm}$; Child-Pugh grading class B or class $\mathrm{C}$. Mortality, morbidity and recurrence rates were analyzed.

Results: A total of 18 patients were included. There was no conversion to open operation. The mean operation time was $105 \mathrm{~min}$ (range, 70 155 min) and the mean blood loss during operation was $95 \mathrm{ml}$ (range, 40 160 ml). No patient needed blood transfusion. The complications after operation included: pneumonia in 1 patient and mild transient jaundice in 2 patients $(<45 \mu \mathrm{mol} / \mathrm{L})$. None developed ascites, coagulopathy, or encephalopathy. There were no postoperative bile leaks, hepatic failure, and death. The mean hospital stay was $9.5 \mathrm{~d}$ (7 16 d). Complete tumor necrosis was found in 14 patients, while tumor cells were found in the resected specimen of the 4 other patients by pathological examination. The mean resection margin was $8.3 \mathrm{~mm}$ (range, 6 11 mm). After a mean follow-up of 13 months (range, 5 28 months), 2 patients (2/18) developed tumor recurrence in the liver.

Conclusion: Our study shows that microwave coagulation therapy combined with laparoscopic liver resection for hepatocellular carcinoma in cirrhotic patients is feasible and safe.

Keywords: Laparoscopy; Hepatocellular carcinoma; Microwave; Cirrhosis

\section{Introduction}

Hepatocellular carcinoma (HCC) is a common malignant disease worldwide. Partial hepatectomy remains the best hope for a cure but is suitable for only $9 \%$ to $27 \%$ of patients [1]. The presence of severe liver cirrhosis often precludes hepatectomy in patients with HCC due to high hepatic failure rate after operation. In the past decade, imageguided thermal ablation as a minimally invasive technique has been widely used for the treatment of small HCC in patients who have high surgical risks [2,3].With improvements in devices and techniques, radiofrequency ablation (RFA) and microwave coagulation therapy (MWCT) have displayed potential capability for treating HCC measuring larger than $3 \mathrm{~cm}$ [4-6]. However, the complete ablation rate can reach only $89 \% \sim 98.6 \%$ using thermal ablation [7-9]. Moreover, increased risk of tumor seeding after percutaneous thermal ablation for HCC remains [10]. Theoretically, surgical resection of the tumor after thermal ablation will take advantage of reducing the risk of tumor residual without increasing the risk of hepatic failure. Recently, laparoscopic resection of liver tumors has been developed and could reduce morbidity [11]. Laparoscopic liver resection for HCC in selected patients is a safe procedure with very good midterm results [12]. In this study, we used microwave coagulation combined with surgical resection under laparoscopy for HCC with severe liver cirrhosis to evaluate the feasibility and safety of this technique.

\section{Patients and Methods}

\section{Patients}

From November 1, 2008, to October 31, 2010, 18 patients (15 men and 3 women; age range, 35-77 years) with HCC and associated severe liver cirrhosis underwent microwave coagulation therapy combined with laparoscopic liver resection at the Department of Hepatobiliary Surgery, Sun Yat-sen Memorial Hospital of the Sun Yat-sen University, Guangzhou, China. The diagnosis was confirmed by both serum alpha-fetoprotein (AFP) and computed tomography (CT) scan or magnetic resonance imaging (MRI). This study was carried out after approval by the university teaching hospital ethics committee and informed consent of the patient. Selection criteria of patient in this study were as follows: solitary, peripheral or subcapsular HCC lesions localised to the left or anterior right (IVb-V-VI) segments; lesion size 
Citation: Zhang H, Xuan YC, Luo X, Cao J (2014) Microwave Coagulation Therapy Combined with Laparoscopic Liver Resection for Hepatocellular Carcinoma in Cirrhotic Patients. Journal of Vascular Medicine \& Surgery 2: 134. doi:10.4172/2329-6925.1000134

Page 2 of 4

less than $4 \mathrm{~cm}$; Child-Pugh grading class $\mathrm{B}$ or class $\mathrm{C}$, the 15 -min retention rate for indocyanin green (ICGR15) more than $20 \%$ and less than 35\%; American Society of Anesthesiologists (ASA) risk group 1 or 2; normal cardiac and pulmonary function. The characteristics of the 18 patients are summarised in (Table 1 ).

\begin{tabular}{|c|c|c|c|c|c|c|c|c|}
\hline No. of patients & Gender & Age (yrs) & Child-Pugh Class & $\begin{array}{l}\text { Lesion size } \\
(\mathrm{cm})\end{array}$ & Location (segment) & $\begin{array}{l}\text { Serum } \\
(\mu \mathrm{g} / \mathrm{L})\end{array} \quad \mathrm{AFP}$ & ICGR15 (\%) & $\begin{array}{l}\text { Resection margin } \\
(\mathrm{mm})\end{array}$ \\
\hline 1 & male & 40 & C & 2.5 & $\mathrm{IVb}$ & 122.5 & 26.1 & 10 \\
\hline 2 & male & 35 & B & 3.7 & $\mathrm{IVb}$ & 328 & 23.6 & 8 \\
\hline 3 & male & 48 & B & 3.2 & v & 380.6 & 21.8 & 10 \\
\hline 4 & male & 46 & B & 3.8 & III & 468 & 25.3 & 7 \\
\hline 5 & female & 62 & B & 3.9 & VI & 611.5 & 20.8 & 6 \\
\hline 6 & male & 51 & B & 3.5 & $\mathrm{VI}$ & 425 & 22.5 & 9 \\
\hline 7 & male & 53 & C & 3 & $\mathrm{IVb}$ & 186.3 & 24.8 & 8 \\
\hline 8 & male & 39 & B & 3.2 & v & 275 & 21.1 & 11 \\
\hline 9 & female & 54 & B & 3.8 & V & 408.5 & 22.8 & 7 \\
\hline 10 & male & 50 & B & 3.3 & VI & 265.2 & 26.6 & 10 \\
\hline 11 & male & 56 & B & 3.6 & III & 359.5 & 25.8 & 8 \\
\hline 12 & male & 52 & B & 3.4 & VI & 416 & 23.1 & 10 \\
\hline 13 & male & 49 & B & 2.8 & VI & 232.8 & 25.7 & 9 \\
\hline 14 & male & 55 & B & 3.5 & VI & 368 & 21.3 & 8 \\
\hline 15 & male & 77 & B & 3.1 & V & 453.6 & 34.2 & 6 \\
\hline 16 & female & 56 & B & 3 & $\mathrm{IVb}$ & 306.1 & 22.3 & 7 \\
\hline 17 & male & 42 & B & 3.5 & III & 517.2 & 23.3 & 7 \\
\hline 18 & male & 47 & B & 3.3 & $\mathrm{IVb}$ & 482 & 25.9 & 8 \\
\hline
\end{tabular}

Table 1: Characteristics of 18 patients treated with MWCT and resection under laparoscopy

\section{Surgical Techniques}

Operation was performed under general anesthesia. Firstly, an incision was made below the umbilicus and a Veress needle was inserted into the peritoneum. Carbon dioxide (CO2) was used to insufflate the abdominal cavity to facilitate the view and abdominal pressure was electronically maintained at $12 \mathrm{~mm} \mathrm{Hg}$. Two 5-mm and one $10-\mathrm{mm}$ trocars were inserted into the abdominal cavity for manipulation. The liver was examined by vision and laparoscopic ultrasound (US) to confirm the extension of the lesions and define their relationship with the intrahepatic vascular structures. After laparoscopic examination, a cooled-shaft microwave system (FORSEA MTC-3C; Qinghai Mirowave Electronic Institute, Nanjing, China) which had 21-gauge thermocouple needles was used. In general, microwave antennae were inserted percutaneously into the tumor lesion and multiple single antennae were used [13]. An output setting of $60 \mathrm{~W}$ for $8 \sim 10$ mins was routinely used during coagulation sessions. After microwave coagulation of the tumor, the antennae were gradually withdrawn and microwave emission was continued for 2 mins under surveillance of laparoscopy before the antennae were pulled out. This method helped prevent tumor seeding. After microwave coagulation, non-anatomic resection of the tumor and an intended $1 \mathrm{~cm}$ tumor free margin was performed under laparoscopy.
Hepatic transection was performed with a harmonic scalpel (Ultracision, Ethicon, USA) and a bipolar vessel sealing device (Ligasure; Valleylab). Bipolar electrocoagulation was used for minor bleeding, and larger structures were secured with clips. The resected specimen was put into a plastic bag and taken out from the prolonged umbilicus incision. This incision was closed and the abdomen reinflated. The surgical field was checked for bleeding or bile leak and abdominal drainage was usually placed.

\section{Follow-Up}

Patients with chronic hepatitis B and active viral replication were treated with entecavir (Sino-American Shanghai Squibb Pharmaceuticals Ltd., Shanghai, China), which started preoperatively. Follow-up included liver function tests, alpha-fetoprotein, and CT scan or MR imaging every 2 months in the first 6 months and then every 3 months after operation. Follow-up ended at the time of death or at last clinical visit before March 31, 2011.

\section{Results}

Eighteen patients with HCC underwent microwave coagulation therapy combined with surgical resection under laparoscopy. There 
was no conversion to open operation. The mean operation time was $105 \mathrm{~min}$ (range, 70 155 $\mathrm{min}$ ) and the mean blood loss during operation was $95 \mathrm{ml}$ (range, $40 \sim 160 \mathrm{ml}$ ). No patient needed blood transfusion. The complications after operation included: pneumonia in 1 patient and mild transient jaundice in 2 patients $(<45 \mu \mathrm{mol} / \mathrm{L}$, normal value $<21 \mu \mathrm{mol} / \mathrm{L}$ ). None developed ascites, coagulopathy, or encephalopathy. There were no postoperative bile leaks, hepatic failure, and death. The mean hospital stay was $9.5 \mathrm{~d}(7 \sim 16 \mathrm{~d})$. Complete tumor necrosis was found in 14 patients, while tumor cells were found in the resected specimen of the 4 other patients by pathological examination. The mean resection margin was $8.3 \mathrm{~mm}$ (range, 6 11 mm).

After a mean follow-up of 13 months (range, 5 28 months), 2 patients $(2 / 18)$ developed tumor recurrence in the liver. One patient had local recurrence in the same liver segment and the recurrence of the other patient occurred in another segment. Both patients underwent microwave coagulation therapy again.

\section{Discussion}

Partial hepatectomy remains the best hope for a cure for HCC. The presence of significant background cirrhosis often precludes liver resection in patients with HCC [14]. Image-guided thermal ablation as a minimally invasive technique has been widely used for the treatment of small HCC in patients who have high surgical risks [2,3]. However, the complete ablation rate can reach only $89 \%$ $98.6 \%$ using thermal ablation [7-9]. Moreover, increased risk of tumor seeding after percutaneous thermal ablation for HCC remains [10]. In our study, viable tumor cells were found in the resected specimen of 4 patients after MWCT and all the lesion sizes of them were larger than $3.6 \mathrm{~cm}$. Up to now, the complete ablation rate of local thermal ablation has not reached $100 \%$ even in small tumors, and local thermal ablation yields lower rates of $53-61 \%$ for medium-sized tumors (diameter $3.1 \sim 5 \mathrm{~cm}$ ) [15]. Because the thermal ablation zone is circular, however the shapes of some tumors are not circular. This is the main cause of viable rest tumor cells after MWCT for medium-sized tumors. Hence, we used microwave coagulation combined with surgical resection under laparoscopy for HCC with severe liver cirrhosis to avoid the viable rest tumor cells after MWCT.

The feasibility of the procedure in our selected patients was $100 \%$ without conversion to open operation. It should be emphasized that considering laparoscopic hepatectomy requires 2 conditions: 1) strict patient selection in terms of tumor location and size, and 2) specific expertise and training, in both open hepatic resection and laparoscopic surgery [12]. The most important factors in the selection of candidates for laparoscopic resections are the location of the tumor and size $[11,16,17]$. According to the literature, small (less than $5 \mathrm{~cm}$ in diameter), peripheral or superficial lesions constitute a good indication for the laparoscopic hepatic resection [11]. In our cohort, tumor lesions were located in segment III, IV, V and VI. These locations allow a good exposure of the whole operation field and safe vascular control. However, no lesion located in segment VII was treated because of the diffculty of exposure. Ahead of this study, we had completed a series of laparoscopic liver resection for liver neoplasms and suggested that laparoscopic hepatectomy may be safe and feasible in selected patients [18].

The safety of the procedure is attested by the absence of mortality and specific morbidity. Ascites and liver failure are the main complications of liver resection in cirrhotic patients. In our study, there was no postoperative ascites, hepatic failure, and death. Other specific complications after hepatectomy such as bile leak or postoperative bleeding, which is another indicator of the safety of the procedures, were not found in our patients.

The advantages of MVCT combined with surgical resection under laparoscopy for HCC with severe liver cirrhosis included: reduction of blood loss during hepatectomy, decreased risk of tumor residual, and avoidance of accidental injury of viscera which might occur in the traditional image-guided MVCT. Since laparoscopic hepatectomy was performed after MVCT, most of the small vessels around the margin of liver tumor had been sealed by coagula while hepatic transection was performed. Moreover, laparoscopic surgery may provide better visualization of vascular structures and more precise and accurate surgery. Some studies comparing laparoscopic versus open procedures have demonstrated that the laparoscopic procedure may well be associated with less blood loss than open equivalents [16,17]. This observation may be due to the tamponading effect of a pneumoperitoneum [19]. Hence, blood loss could be minimized with this technique. Furthermore, the resection margin usually should be more than $2 \mathrm{~cm}$ in radical resection of HCC. However, liver tissue should be preserved as much as possible to decrease the risk of liver failure in the patients with severe cirrhosis. Performing MWCT before laparoscopic surgical resection, the resection margin can be minimized to $1 \mathrm{~cm}$ due to the local thermal ablation.

Although percutaneous image-guided thermal ablation has been widely used for the treatment of small HCC, accidental injury of viscera such as bile duct injury, perforation of colon or stomach, which might occur in the traditional image-guided MVCT [11]. However, such accidental injury can be avoided by the laparoscopic surveillance when MVCT was performed. On the other hand, tumor residual after thermal albation is still the main reason of HCC recurrence. In our study, complete tumor necrosis was only found in 14 patients, while tumor cells were found in the resected specimen of the 4 other patients by pathological examination. Hence, laparoscopic resection of the HCC lesions after MVCT can decrease the risk of tumor residual.

With the laparoscopic approach several advantages can be obtained: early mobilisation and feeding, decreased postoperative pain, reduction of respiratory complication, shorter hospital stay, earlier commencement of adjuvant therapy [11]. Moreover, a lesser destruction of abdominal wall porto-systemic shunts may reduce the increase of portal hypertension and consequent postoperative bleeding [11].

Our study shows that microwave coagulation therapy combined with laparoscopic liver resection for hepatocellular carcinoma in cirrhotic patients is feasibl and safe. Since the number of patients in our study is limited, further prospective evaluations are required to assess the long term results of this procedure.

\section{References}

1. Lai EC, Fan ST, Lo CM, Chu KM, Liu CL, et al. (1995) Hepatic resection for hepatocellular carcinoma. An audit of 343 patients. Ann Surg 221: 291-298.

2. Chen MS, Li JQ, Zheng Y, Guo RP, Liang HH, et al. (2006) A prospective randomized trial comparing percutaneous local ablative therapy and partial hepatectomy for small hepatocellular carcinoma. Ann Surg 243: 321-328.

3. Liang P, Dong B, Yu X, Yu D, Wang Y, et al. (2005) Prognostic factors for survival in patients with hepatocellular carcinoma after percutaneous microwave ablation. Radiology 235: 299-307. 
Citation: Zhang H, Xuan YC, Luo X, Cao J (2014) Microwave Coagulation Therapy Combined with Laparoscopic Liver Resection for Hepatocellular Carcinoma in Cirrhotic Patients. Journal of Vascular Medicine \& Surgery 2: 134. doi:10.4172/2329-6925.1000134

Page 4 of 4

4. Lu MD, Xu HX, Xie XY, Yin XY, Chen JW, et al. (2005) Percutaneous microwave and radiofrequency ablation for hepatocellular carcinoma: a retrospective comparative study. J Gastroenterol 40: 1054-1060.

5. Gillams AR (2005) The use of radiofrequency in cancer. Br J Cancer 92: 1825-1829.

6. Yin XY, Xie XY, Lu MD, Xu HX, Xu ZF, et al. (2009) Percutaneous thermal ablation of medium and large hepatocellular carcinoma: longterm outcome and prognostic factors. Cancer 115: 1914-1923.

7. Lin SM, Lin CJ, Lin CC, Hsu CW, Chen YC (2004) Radiofrequency ablation improves prognosis compared with ethanol injection for hepatocellular carcinoma $<$ or $=4 \mathrm{~cm}$. Gastroenterology 127: 1714-1723.

8. Lencioni RA, Allgaier HP, Cioni D, Olschewski M, Deibert P, et al. (2003) Small hepatocellular carcinoma in cirrhosis: randomized comparison of radio-frequency thermal ablation versus percutaneous ethanol injection. Radiology 228: 235-240.

9. Shibata T, Iimuro Y, Yamamoto Y, Maetani Y, Ametani F, et al. (2002) Small hepatocellular carcinoma: comparison of radio-frequency ablation and percutaneous microwave coagulation therapy. Radiology 223: 331-337.

10. Llovet JM, Vilana R, Brú C, Bianchi L, Salmeron JM, et al. (2001) Increased risk of tumor seeding after percutaneous radiofrequency ablation for single hepatocellular carcinoma. Hepatology 33: 1124-1129.

11. Belli G, Fantini C, D'Agostino A, Belli A, Russolillo N (2004) Laparoscopic liver resections for hepatocellular carcinoma (HCC) in cirrhotic patients. HPB (Oxford) 6: 236-246.
12. Cherqui D, Laurent A, Tayar C, Chang S, Van Nhieu JT, et al. (2006) Laparoscopic liver resection for peripheral hepatocellular carcinoma in patients with chronic liver disease: midterm results and perspectives. Ann Surg 243: 499-506.

13. Liang $\mathrm{P}$, Wang $\mathrm{Y}, \mathrm{Yu} \mathrm{X}$, Dong B (2009) Malignant liver tumors: treatment with percutaneous microwave ablation--complications among cohort of 1136 patients. Radiology 251: 933-940.

14. Lau WY, Leung TW, Yu SC, Ho SK (2003) Percutaneous local ablative therapy for hepatocellular carcinoma: a review and look into the future. Ann Surg 237: 171-179.

15. Lin SM (2013) Local Ablation for Hepatocellular Carcinoma in Taiwan. Liver Cancer 2: 73-83.

16. Morino M, Morra I, Rosso E, Miglietta C, Garrone C (2003) Laparoscopic vs open hepatic resection: a comparative study. Surg Endosc 17: 1914-1918.

17. Lesurtel M, Cherqui D, Laurent A, Tayar C, Fagniez PL (2003) Laparoscopic versus open left lateral hepatic lobectomy: a case-control study. J Am Coll Surg 196: 236-242.

18. Zhang L, Chen YJ, Shang CZ, Zhang HW, Huang ZJ (2009) Total laparoscopic liver resection in 78 patients. World J Gastroenterol 15: 5727-5731.

19. Spencer L, Metcalfe MS, Strickland AD, Elsey EJ, Robertson GS, et al. (2008) Lessons from laparoscopic liver surgery: a nine-year case series. HPB Surg 2008: 458137. 